\title{
LEI DO RESFRIAMENTO DE NEWTON:TEORIA E PRÁTICA
}

\section{LEY DE REFRIGERACIÓN DE NEWTON: TEORÍA Y PRÁCTICA}

\section{NEWTON COOLING LAW: THEORY AND PRACTICE}

\author{
Pedro Augusto Soares da Silva ${ }^{1}$; Nallyson Francisco Silva Souza ${ }^{2}$; Leandro Campos da \\ Cunha $^{3}$; José Gomes Ferreira Filho ${ }^{4}$; Roberto Arruda Lima Soares ${ }^{5}$
}

DOI: https://doi.org/10.31692/978-65-991061-3-2.146-151

\section{INTRODUÇÃO}

A necessidade de contextualizar situações em sala de aula, onde o professor constrói ocasiões que fiquem mais acessíveis para o entendimento dos alunos, é uma boa abordagem de ensino, pois uma teoria com significado para os alunos pode proporcionar uma melhor aprendizagem. Contudo, a teoria na Matemática tem sua importância, pois leva ao aluno o motivo pelo qual aquele conteúdo foi estudado, revelando as necessidades que fizeram com que o homem buscasse criar e desenvolver respostas para o que acontecia ao seu redor.

Uma boa explanação do conteúdo, por parte do professor, pode induzir nos alunos curiosidades sobre o conteúdo estudado, onde eles por meio da aula prática podem construir um conhecimento mais significativo, observando a importância tanto da teoria quanto da prática no cotidiano das pessoas. Neste trabalho, é observado que o ensino da matemática associando aspectos teóricos e aplicações prática podem ser utilizadas de uma forma a instigar os alunos a confirmarem suas conclusões teóricas. Com isso, aprender matemática se torna mais atrativo e prazeroso, ou seja, a ideia de que a matemática é somente cálculos soltos sem muita aplicação. Com esse tipo de estudo o aluno muda a sua forma de interpretar os diversos acontecimentos, formando cidadãos críticos e construtores do conhecimento.

Este estudo baseou-se nas Equações Diferenciais, na parte da Lei de Resfriamento de Newton, associando a teoria e prática para o desenvolvimento do trabalho. A Lei de Resfriamento de Newton foi utilizada com a intenção de ser simples e compreensível, buscando demonstrar como o aprendizado pode se tornar prazeroso quando conseguimos associar conceitos teóricos ao nosso cotidiano.

\section{FUNDAMENTAÇÃO TEÓRICA}

\footnotetext{
${ }^{1}$ Licenciatura Matemática, IFPI, pedroaugusto.thay00@gmail.com

${ }^{2}$ Licenciatura Matemática, IFPI, nallysonsouza0202@gmail.com

${ }^{3}$ Licenciatura Matemática, IFPI, Ldrocampos@ hotmail.com

${ }^{4}$ Licenciatura Matemática, IFPI, jogofefi@gmail.com

${ }^{5}$ Professor Doutor, IFPI, robertoarruda@ifpi.edu.br
} 
A Lei de Resfriamento de Newton é uma aplicação em equações diferenciais utilizada para resolver problemas relacionados à variação de temperatura, assim como afirma Alitolif (2011),

Esta forma de aplicação é ligada diretamente a física, mas cálculos voltados para as leis de temperatura são de grande utilidade em várias outras ciências, alguns exemplos são os utilizados nas engenharias, na variação de temperatura de uma simples xícara de café durante o seu resfriamento ou no derretimento de uma bola de sorvete, ou ainda no processo de resfriamento de um bolo, entre outras aplicabilidades deste modelo. (ALITOLIF, 2011, p.18).

Um dos motivos da evasão escolar, possivelmente, é ocasionada em suma pela falta de interesse do aluno em acompanhar um conteúdo que não o estimule, uma vez que esses não são apresentados de forma a dar significado em sua vida, pois o professor não traz o conteúdo para a realidade, trata apenas de cenários nunca vistos por estes, fazendo com que o desinteresse tome conta dos alunos. Assim como afirmam, Lisboa e Lucino (2015). Por este motivo, é fundamental que os professores busquem novas alternativas educacionais capazes de manter o interesse entre a matemática escolar aplicada com o meio em que os alunos vivem. Assim, D’Ambósio (1986) complementa que,

O valor da teoria se revela no momento em que ela é transformada em prática. No caso da educação, as teorias se justificam na medida em que seu efeito se faça sentir na condução do dia-a-dia na sala de aula. De outra maneira, a teoria não passará de tal, pois não poderá ser legitimada na prática educativa. (D`AMBROSIO, 1986, p. 43).

\section{METODOLOGIA}

O trabalho foi desenvolvido no sexto módulo do curso de Licenciatura em Matemática, sob a orientação do Pr. Dr. Roberto Arruda Lima Soares, no Campus Teresina Central do Instituto Federal de Educação, Ciência e Tecnologia do Piauí. Este trabalho se estrutura em duas etapas: a primeira visa uma pesquisa bibliográfica sobre a Lei de Resfriamento de Newton através de livros, artigos científicos, documentos, revistas acadêmicas e sites educacionais. $\mathrm{Na}$ segunda etapa fez-se experimento com a utilização de alguns instrumentos (estufa, termômetro digital, objeto de material cerâmico, objeto de material metálico, bloco de anotações, caneta, etc.) e a partir dos dados coletados foi desenvolvida uma situação-problema por meio da Lei de Resfriamento de Newton, com isso, os resultados obtidos por meio do método teórico foram 
comparados com o método prático e posterior análise dos resultados obtidos. O estudo foi realizado por meio da leitura prévia e individual de obras na disciplina de matemática, para as discussões sobre a Lei de Resfriamento de Newton e suas aplicações, foi utilizado neste trabalho computadores com acesso à Internet, livros e artigos científicos que discutem o assunto.

\section{RESULTADOS E DISCUSSÕES}

Na tentativa de contextualizar a união entre teoria e prática através da Lei de Resfriamento de Newton foi realizado um experimento que trabalha com o uso de um termômetro eletrônico medir a temperatura do ambiente (laboratório de materiais), em seguida, o material cerâmico é retirado da estufa e colocado numa superfície em temperatura ambiente $\left(27,8^{\circ} \mathrm{C}\right), \operatorname{logo}$ após, com intervalos de 30 segundos são feitas as medições da temperatura deste material.

Assim, foram obtidos os seguintes valores:

Tabela 1: Resultado do experimento com material cerâmico

\begin{tabular}{|c|c|}
\hline \multicolumn{2}{|c|}{ Resultado do experimento com material cerâmico } \\
\hline Temperatura da estufa & $110,6^{\circ} \mathrm{C}$ \\
\hline Tempo (t) em minutos & Temperatura (T) em ${ }^{\circ} \mathrm{C}$ \\
\hline $0^{\prime}$ & 95,9 \\
\hline $30^{\prime \prime}$ & 93,2 \\
\hline $1^{\prime}$ & 88,4 \\
\hline $1^{\prime} 30^{\prime \prime}$ & 83,3 \\
\hline $2^{\prime}$ & 78,9 \\
\hline $2^{\prime} 30^{\prime \prime}$ & 72,8 \\
\hline $3^{\prime}$ & 69,8 \\
\hline $3^{\prime} 30^{\prime \prime}$ & 65,2 \\
\hline $4^{\prime}$ & 56,9 \\
\hline $4^{\prime} 30^{\prime \prime}$ & 59,7 \\
\hline $5^{\prime}$ & 56,9 \\
\hline & \\
\hline & \\
\hline & \\
\hline & \\
\hline & \\
\hline
\end{tabular}

Fonte: Própria (2018). 
Em seguida com o material metálico foi realizado o mesmo procedimento, onde é retirado da estufa e colocado numa superfície em temperatura ambiente $\left(27,8^{\circ} \mathrm{C}\right), \operatorname{logo}$ após, com intervalos de 30 segundos são feitas as medições da temperatura deste material.

Assim, foram obtidos os seguintes valores:

Tabela 2: Resultado do experimento com material metálico.

\begin{tabular}{|c|c|}
\hline \multicolumn{2}{|c|}{ Resultado do experimento com material metálico } \\
\hline Temperatura da estufa & $110,3^{\circ} \mathrm{C}$ \\
\hline Tempo (t) em minutos & Temperatura $(\mathrm{T}) \mathrm{em}{ }^{\circ} \mathrm{C}$ \\
\hline $0^{\prime}$ & 90,3 \\
\hline $30 "$ & 76,8 \\
\hline 1' & 67,1 \\
\hline 1'30" & 60,2 \\
\hline $2^{\prime}$ & 56,7 \\
\hline 2'30" & 53,4 \\
\hline $3^{\prime}$ & 50,4 \\
\hline 3’30" & 47,8 \\
\hline $4^{\prime}$ & 45,3 \\
\hline 4'30" & 43,6 \\
\hline $5^{\prime}$ & 41,9 \\
\hline
\end{tabular}

Fonte: Própria (2018)

Então foram feitos os cálculos por meio da aplicação teórica na Lei de Resfriamento de Newton resolvendo a seguinte situação: Num quarto fechado, cuja temperatura ambiente permanece a $27,8^{\circ} \mathrm{C}$ coloca-se um determinado objeto cerâmico a uma temperatura constante de $95,9^{\circ} \mathrm{C}$. Se após 1 minuto a temperatura do objeto for de $88,4^{\circ} \mathrm{C}$ determine a temperatura deste com intervalo de 30 segundos até o tempo de 5 minutos. Assim como para um objeto metálico à $90,3^{\circ} \mathrm{C}$, que após 1 minuto está à $67,1^{\circ} \mathrm{C}$.

\section{CONCLUSÕES}


O presente trabalho teve como propósito mostrar a importância da fusão entre teoria e prática no ensino/aprendizagem de Matemática, além de conhecer e estudar a história das equações diferenciais ordinárias e a Lei de Resfriamento de Newton. Foi contextualizada a união das aplicações teóricas e práticas através de uma situação-problema resolvida por meio da lei de resfriamento de Newton e de um experimento.

O experimento trouxe a possibilidade de usar o modelo da lei de Resfriamento de Newton em uma prática e comparar os resultados práticos com os já sabidos da teoria como forma de prova, analisando os erros absolutos e relativos para cada intervalo de tempo analisado.

$\mathrm{Na}$ comparação dos valores obtidos foram observadas poucas mudanças nas temperaturas com intervalos de 1 e 5 minutos para o resfriamento do metal e da cerâmica. Com isso, a aprendizagem tornou-se significativa quando foi possível compreender os fenômenos físicos capazes de explicar porque um corpo perde calor com o passar do tempo e que a escolha dos instrumentos da pesquisa também foi influenciada nos resultados.

Por isso, torna importante ressaltar que o docente deve tentar desenvolver práticas pedagógicas diferenciais para auxiliar no desenvolvimento cognitivo do discente, pois quando nos encontramos totalmente envolvidos com a nossa realidade fantástica em estudo surge então à obtenção de novos conceitos como também nos sentimos responsáveis pela nossa própria aprendizagem.

\section{REFERÊNCIAS}

ALITOLEF, S. S. Algumas Aplicações das Equações Diferenciais. Ji Paraná: UNIR, 2011.

D'AMBROSIO, U. Da realidade à ação: reflexões sobre educação e matemática. $1^{\text {a }}$ ed. São Paulo: Summus, 1986.

FRAZÃO, D. Isaac Newton. Disponível em <

https://www.ebiografia.com/isaac_newton > Acesso em nov. 2018.

GHAJAR, A. J.; ÇENGEL, Y. A. Transferência de Calor e Massa: Uma abordagem prática. Tradução de Fátima A. M. Lino. 4ª ed. São Paulo: Bookman, 2012.

LIMA, S. F. Erros e Medições Físicas. Disponível em < http://aprendendofisica.pro.br/pmwiki.php/Main/ErrosMedidasFisicaEEtc > . Acesso em nov. 2018.

LISBOA, J.; LUCINO, M. A. A importância da teoria e prática nas aulas de matemática. Ivaiporã: FIVI, 2015. 
Medição de dados experimentais, incerteza e propagação de erro. Página elaborada pela FEM - FACULDADE DE ENGENHARIA MECÂNICA. Medição de dados experimentais...

PEREIRA, I. M. do N.;BARBOZA, C. M. Teoria e prática na lei de resfriamento de Newton. EMD, p.45-53. 2018. 